\title{
Clinical experience in the use of dexmedetomidine
}

CLÍNIC

\section{BARCELONA}

Hospital Universitari

\section{for deep brain stimulation}

Belda I; Valero R; Carrero E; Hurtado P; Gracia I; Fàbregas N.

Neuroanesthesia Section. Anesthesiology Department. Hospital Clínic de Barcelona. ibelda@clinic.cat

\section{Background}

$\checkmark$ Dexmedetomidine (DEX) is an alpha ${ }_{2}$-adrenergic agonist that produces sedation through the promotion of endogenous sleep pathway activities without respiratory depression. ${ }^{1}$

$\checkmark$ It seems not to interfere with electrophysiological records (EPRs) and neurocognitive tests (NTs) during deep brain stimulation procedures (DBS). ${ }^{2,3}$ It was approved as for "out of label" indication in our hospital in 2014.

The goal of this study was to confirm the usefulness of DEX for DBS in patients with movement disorders in our setting.

\section{Methods}

A prospective observational study was conducted. Patients scheduled for deep brain stimulation (DBS) during 2015-2016 were included. (Fig.1) PROCEDURE:

- The stereotaxic frame was placed under local anaesthesia.

- Monitoring included electrocardiogram, pulse oximeter, $\mathrm{BIS}^{\oplus}$, capnography and invasive blood pressure (arterial line). $\mathrm{O}_{2}$ was provided through nasal prongs.

- A total of $1 \mu \mathrm{g} . \mathrm{kg}^{-1}$ of DEX was administered within 10 minutes at the beginning of the procedure, followed by perfusion $\left(0.1-1 \mu g \cdot \mathrm{kg}^{-1} \cdot \mathrm{h}^{-1}\right)$ adjusted as needed.

- All patients received $1 \mu \mathrm{gg} \cdot \mathrm{kg}^{-1}$ of fentanyl. If necessary, propofol and remifentanil were added in bolus or "target controlled infusion" system. - Sedation was assessed by means of Richmond Scale (RASS).

- Ropivacaine $\mathbf{0 . 7 5 \%}+$ Lidocaine $2 \%$ was used for bilateral 'scalp block' prior to cranial incision.

- Analyzed variables were sedation level, patient comfort by Visual Analogue Scale (VAS), hemodynamic and respiratory parameters, intraoperative and postoperative adverse effects.

- The correct placement of the electrodes, guided by EPRs and possible incidences during NTs were recorded. (Fig.2 and 3).

\section{Results}

Seventeen consecutive patients who underwent DBS during the study period were included (14 Parkinson, 2 essentials tremors and 1 dystonia).

\begin{tabular}{|c|c|}
\hline \multicolumn{2}{|c|}{ Summary description of the analyzed parameters } \\
\hline RASS & -1 a -3 (-4 in 1 patient) \\
\hline DEX perfusion & $0.5 \pm 0.2 \mu \mathrm{g} \cdot \mathrm{kg}^{-1} \cdot \mathrm{h}^{-1}$ \\
\hline Adjuvants drugs & $\begin{array}{l}\text { Propofol (5) } \\
\text { Remifentanil (3) } \\
\text { Propofol + Remifentanil (3) }\end{array}$ \\
\hline VAS & $\begin{array}{l}\text { All patients VAS }<3 \text {, } \\
\text { except } 1 \text { patient with VAS } 5 \text { (high } \\
\text { previous consumption of opioids) }\end{array}$ \\
\hline Hemodynamic incidences & $\begin{array}{l}\text { Bradycardia (atropine) (1) } \\
\text { Hypotension (phenylephrine) (1) } \\
\text { Hypertension (urapidil) (7) } \\
\text { Hypertension (clevidipino) (1) }\end{array}$ \\
\hline Respiratory depression & None \\
\hline Adverse effects & $\begin{array}{l}\text { Postoperative agitation (1) } \\
\text { Pneumocephalus (1) }\end{array}$ \\
\hline Neurophysiological records & Optimal in all cases \\
\hline Neurocognitives tests & Correct without drug interference \\
\hline
\end{tabular}

Table 1. Procedures evolution. (Numbers of patients between brackets)

\section{Conclusion}

In our experience, DEX provided conscious sedation and comfort without respiratory depression and with an appropriate hemodynamic profile.

We did not detect interferences with NTs or EPRs and surgeons were comfortable during DBS location in our patient population.

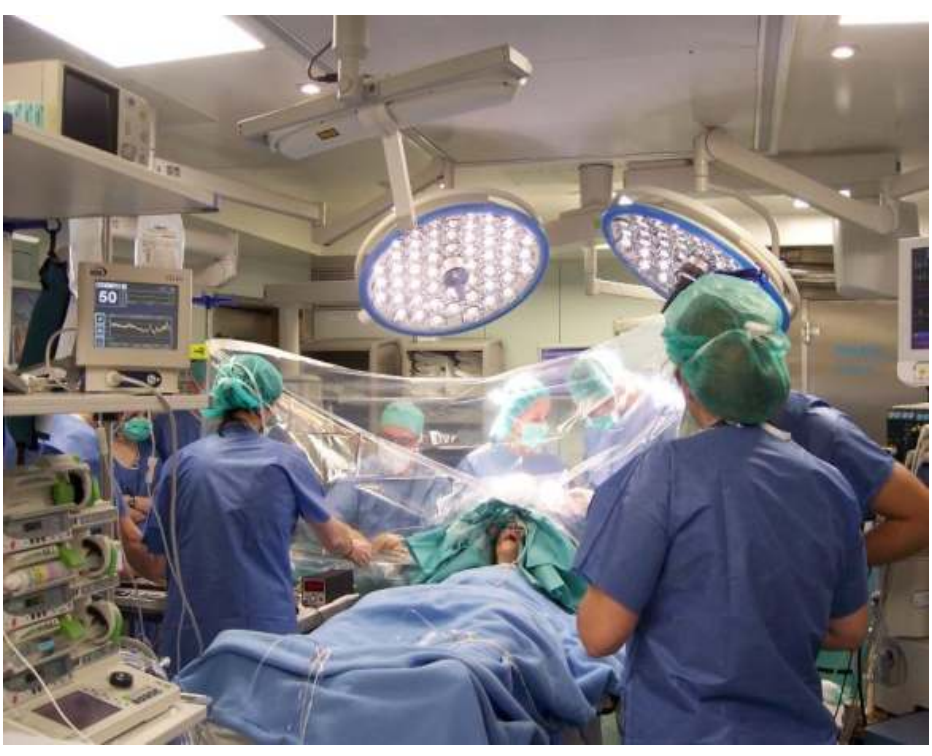

Figure 1. Procedure and position

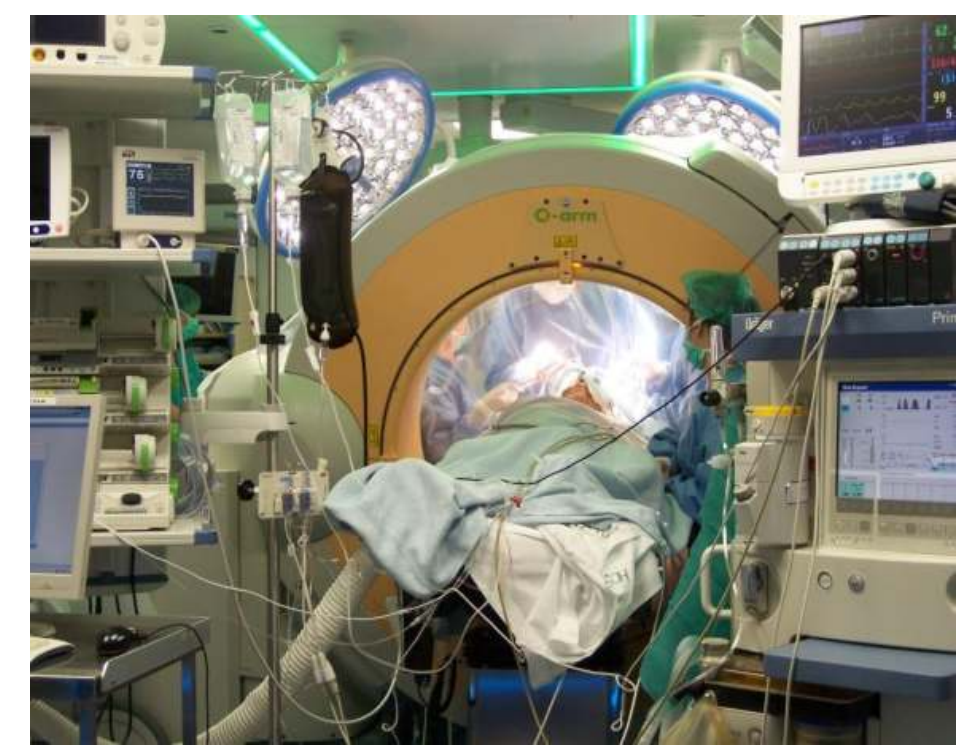

Figure 2. Monitoring and intraoperative O-Arm CT scan

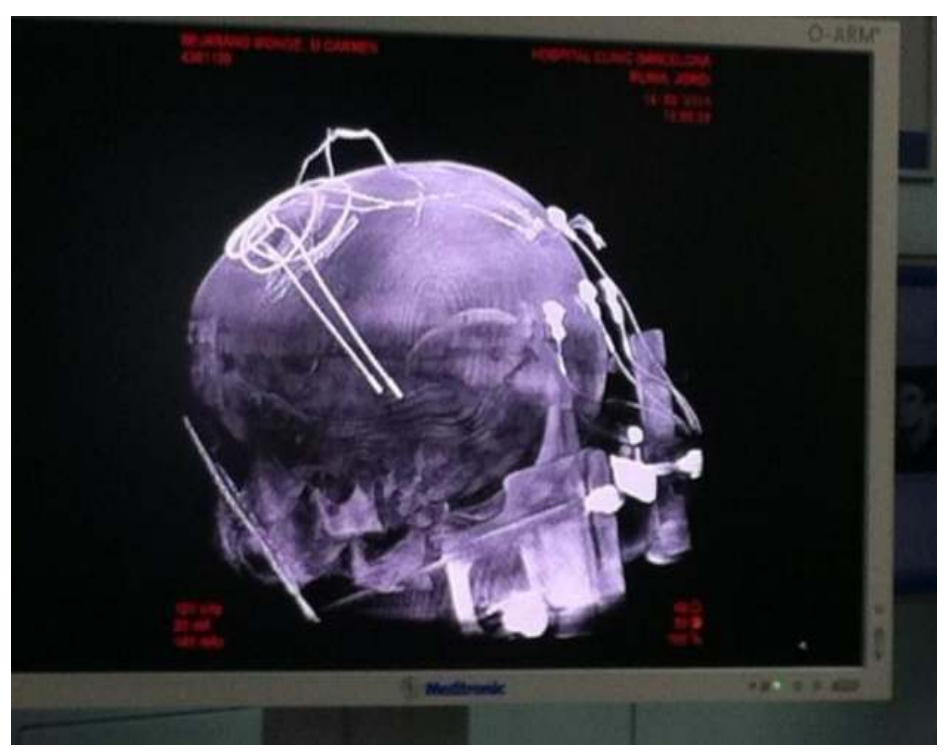

Figure 3. CT 3D reconstruction to check electrodes placement

REFERENCES:

1. Rozet I. Anesthesia for functional neurosurgery: the role of dexmedetomidine Curr Opin Anaesthesiol. 2008;21(5):537-543.

2. Grant R, Gruenbaum SE, Gerrard J. Anaesthesia for deep brain stimulation: a review. Curr Opin Anaesthesiol. 2015;28(5):505-510.

3. Martinez-Simon A, Alegre M,et al. Effect of Dexmedetomidine and Propofol on Basal Ganglia Activity in Parkinson Disease: A Controlled Clinical Trial. Anesthesiology. 2017;126(6):1033-1042. 